ga experiência possibilita a superação de contingências que surgem e autoriza à Conferência traçar com firmeza o seu caminhar na progressiva solidificação da "comunidade jurídica do gênero humano", propugnada por Jitta.

Esta breve exposição tem ainda o propósito de fomentar a curiosidade e o estudo deste complexo fenômeno associativo contemporâneo - o das organizações internacionais que se destinam à criação de normas jurídicas, como também o de aguçar o interesse dos juristas nacionais para esta área extremamente complexa do Direito, que evidencia extraordinária relevância nas relações jurídicas da atualidade e que compõem o universo normativo dos sistemas jurídicos nacionais, além do legislador ordinário.
Por fim, entendemos ter sido providencial a adesão do Brasil ao Estatuto da Conferência da Haia, pois, ao tornar-se membro efetivo desta importante organização internacional, repara o equívoco de ter, no passado, denunciado aquele instrumento.

Com a sua volta à Conferência da Haia, o Brasil cria um espaço no cenário internacional para contribuições riquíssimas que as nossa experiências internas e internacionais podem oferecer, a exemplo do que ocorreu no processo de elaboração e aprovação da Convenção sobre cooperação internacional e à proteção da criança em matéria de adoção internacional, de 29 de maio 1993, onde, ao lado das delegações dos tradicionais países membros da Conferência, atuou de maneira decisiva. ${ }^{85}$

${ }^{85}$ Quanto ao tema específico desta Convenção, que trata da cooperação internacional em matéria de adoção de menores, ver valioso Artigo da Professora Cláudia Lima Marques: "Notícia sobre a Convenção de Haia sobre Adoção internacional: Perspectivas de cooperação internacional e proteção dos direitos das crianças", publicado na Revista Igualdade - Ministério Público do Paraná, Curitiba, ano IV, n. ${ }^{\circ} \mathrm{XI}$, abr/jun 1996, p. 1 a 15.

\section{Pressupostos e Diferenças de um Direito Dogmaticamente Organizado}

\author{
Prof. Dr. Goão Mauricio Adeodato
}

Professor Titular de Introdução ao Estudo do Direito (Graduação) e de Filosofia do Direito (Mestrado e Doutorado) na Universidade Federal de Pernambuco.

\section{Introdução: objetivos e co- locação metodológica}

1 ste texto pretende apresentar parte de uma teoria sobre o direito moderno, não uma teoria universal para todo e qualquer direito, completando trabalho anteriormente publica$\mathrm{do}^{1}$. Sequer aspira a uma teoria geral do direito na modernidade, pela grande diversidade que isso comportaria. O texto procura fixar mais precisamente um conceito específico de direito (dogmático) dentro de um conceito específico de modernidade. Como objetivo corolário, tenta colocar uma teoria do direito moderno que considere e ajude a compreender algumas diferenças entre as formas de organização do direito postas pelas sociedades e Estados ditos desenvolvidos e aquelas características das periferias subdesenvolvidas de um mundo aparentemente globalizado em torno de capital tecnologia.

Diante dessas metas, as questões propriamente filosóficas só interessam aqui à guisa de introdução ao tema, indispensáveis porém subsidiárias. Indispensáveis enquanto fornecem as bases da metodologia de tratamento do problema do conhecimento e esclarecem- lhes os pressupostos, ao mesmo tempo em que estabelecer alguns pontos de partida, buscando facilitar a compreensão do texto, ainda que o leitor venha a entender por bem discordar do seu conteúdo. Assim, tomam-se aqui duas direções quanto aos pressupostos filosóficos, tentando controlar a ambigüidade e a vagueza quando se fala de um conceito de direito: redução do abismo gnoseológico e do abismo axiológico, que serão esclarecidos a seguir.

Antes de tudo, porém, uma colocação va de que o direito é uma forma de organização inerente às sociedades humanas, a aceitação do conhecido dito latino ubi societas ibi jus, isto é, "onde sociedade, aí direito", onde existe sociedade existe direito, preenchendo a elipse verbal. Esta aceitação aqui é instrumental, sem pretensões de verdade ou validade absolutas. Note-se que importantes filósofos e mesmo juristas a questionaram, tais como Karl Marx, para quem o direito seria uma doença ou pelo menos um remédio contra uma doença da sociedade, um instrumento para servir à dominação do homem pelo homem, tendente a desaparecer em uma sociedade plenamente desenvolvida são, por definição, infinitas. Por isso é preciso metodológica: este trabalho parte da perspecti-

${ }^{1}$ Adeodato, João Maurício: "Modernidade e direito". Revista Ciências Sociais, vol. 3, n ${ }^{\circ}$. Rio de Janeiro: Universidade Gama Filho, 1997, p. 264-279.

Revista da Faculdade de Direito da UFRGS, v. 20, Outubro/2001 
(comunista), sem luta de classes ${ }^{2}$, ou o jusfilósofo anticoercitivista polonês León Petrazycki, que entende a sanção jurídica como substitutivo do amor, pois a civilização é sempre uma progressiva realização do amor entre as pessoas, forma particular de razão emotiva do ser humano ${ }^{3}$.

Com todo o respeito que merecem os autores citados, mantém-se aqui a tese de que é o direito um dos fatores fundamentais para transformação de um mero agrupamento de seres humanos em uma sociedade, de que o termo expressa uma forma de comunicação social que organiza minimamente os contornos indispensáveis à constituição de uma sociedade, daí $u b i$ societas ibi jus.

Corroborando esta base metodológica, muito embora vários autores afirmem a possibilidade de sociedade sem direito, como dito, não parece haver ninguém que defenda a existência de direito em isolamento; para aqueles que vêem algum sentido na palavra "direito", certamente a sociabilidade humana, levando ao agrupamento dos seres humanos em comunidades, parece ser uma conditio sine qua non para o aparecimento de relações jurídicas, pois direito é interação. Portanto, mesmo havendo sociedade sem direito, posição marcadamente minoritária entre os juristas, não se afirma a possibilidade de direito sem "sociedade", esta palavra compreendida no sentido básico de mais de uma pessoa convivendo em algum mesmo lugar simultaneamente, segundo determinadas regras. Um conceito acompanha o outro.

Finalmente, cabe mencionar que existe a dificuldade lógica, ainda que não impossibilidade, de tentar fazer uma ciência ou teoria do direito entendendo-o como algo fadado a o passível de desaparecimento, ou mesmo algo circunstancial, contingente. A mutabilidade de seu objeto sempre foi um problema para os juristas preocupados com a cientificidade de suas pesquisa. Pior do que a mutabilidade parece ser a contingência ${ }^{4}$. Se o direito não é permanente na sociabilidade humana, pode não se justificar uma ciência ou uma filosofia do direito como setor específico do conhecimento.

Fixados esses pontos de partida, podese ir ao que aqui significam os dois abismos que dificultam o conhecimento, com os quais tem de se haver toda filosofia.

\section{Pressupostos filosóficos: o abismo gnoseológico e o abis- mo axiológico}

Uma teoria do direito precisa enfrentar, portanto, o abismo gnoseológico, que dificulta o conhecimento do mundo, e o abismo axiológico, que dificulta a avaliação do mundo. Aí estão os fundamentos da epistemologia e da ética jurídicas.

Pode-se explicar o que aqui se compreende por abismo gnoseológico através de três problemas que o compõem e que precisam ser transpostos ou ao menos tratados pela teoria ${ }^{2}$ Marx, Karl: Das Kapital - Kritik der politischen Ökonomie, Band 1. Marx Engels Werke, Band 23. Berlin: Dietz
Verlag, 1988, p. 99 e 789, ou Marx, Karl e Engels, Friedrich: Manifest der kommunistischen Partei. Berlin: Dietz Verlag, 1989, passim.

${ }^{3}$ Gurvitch, Georges: "Une philosophie intuitionniste du droit: Léon Petrazycki". Archives de Philosophie du Droit et de Sociologie Juridique, cahier duble n. 3-4. Paris: Sirey, 1931, p. 403-420. E Rooney, John: "Polish Legal Theory". Indian Socio-Legal Journal, vol. XVIII No. 1 \& 2. Jaipur: Indian Institute of Comparative Law, 1992 p. 107-114.

${ }^{4}$ Kirchmann, Julius Hermann von: Die Wertlosigkeit der Jurisprudenz als Wissenschaft - Vortrag gehalten in der Juristischen Gesellschaft zur Berlin (1848). Darmstadt: Wissenschaftliche Buchgesellschaft, 1966.

Revista da Faculdade de Direito da UFRGS, v. 20, Outubro/2001 do conhecimento: são as incompatibilidades recíprocas entre: a) evento real; b) idéia (ou "conceito", "pensamento"); e c) expressão lingüística (ou "simbólica"). Estas são as três unidades componentes do conhecimento humano, as quais não podem ser reduzidas uma à outra. Como são todos termos ambiguamente empregados na linguagem filosófica, necessário tentar melhor precisá-los.

Por evento real entende-se aqui o acontecimento único e irrepetível que, aparentemente de maneira independente do sujeito cognoscente, coloca-se presente em sua experiência ${ }^{5}$. Esta experiência, seja sensível, intelectual, de qualquer tipo, parece ser também única e irrepetível. A experiência real, mesmo que a partir de objetos não-reais, como na intelecção, é particularizada, individual, única, irrepetível, e é aqui considerada incognoscível ${ }^{6}$. Todo o individual é, em certo sentido, irracional para o ser humano, pois a individualidade, que é uma das características do mundo real, não se adapta ao aparato cognoscitivo do ser humano, que não consegue proceder sem generalizações. $\mathrm{O}$ individual é irracional por ser irredutivelmente contingente. Há uma novidade radical em tudo o que é real e, por isso, qualquer regra geral estabelecida pela razão seleciona alguns aspectos em detrimento de outros. Seguindo uma forte tradição na cultura filosófica do Ocidente, une-se aqui razão a generalização. Além de qualitativamente ilimitada, pois o individual nunca se repete, a irracionalidade individual é também quantitativamente infinita, pois todo indivíduo pode ser mais e mais decomposto em elementos menos complexos: moléculas, átomos, prótons, quarks, a física enfrenta dificuldades na busca pela unidade da matéria.

O leitor atento deve observar que, mesmo diante de uma experiência intelectual, como a intelecção, o objeto será geral, como o triângulo escaleno ou o teorema de Pitágoras, conseqüentemente irreal e ideal, mas a experiência psíquica diante dele é um evento real na consciência, logo único e irrepetível. Quer dizer, a idéia é sempre geral, mas a experiência de cada idéia ou pensamento por parte deste ou daquele indivíduo não deixa de ser um acontecimento real, passível de observação empírica desde que disponíveis os meios adequados.

Um outro aspecto é diferençar claramente o ideal e o irreal: todo ideal é irreal, no sentido de que não é parte da realidade; mas nem todo irreal é ideal. Dividem a característica da irrealidade, mas não se confundem: ideais são a relação de igualdade e a circunferência perfeitas, são objetos que existem idealmente; irreais são o centauro e a quimera, o imaginário, o fictício, existem apenas no sujeito enquanto fenômeno psíquico. Por isso prefere-se aqui o termo "idéia" para designar o que existe idealmente e o termo "pensamento" para compreender os objetos irreais em sua totalidade.

Assim, por idéia entende-se o estímulo que se completa no sujeito no ambiente de seu defrontar-se com os eventos. Ocorre em uma espécie de síntese, uma generalização ideal combinada com os eventos reais. Uma generalização irreal, portanto, posto que tudo o que é real é particular, mas não imaginária. São essas generalizações que permitem à mente humana pensar conjuntamente eventos, fazer sentido. Alguns outros animais parecem ser capazes de proceder a semelhante operação. A idéia é o resultado de um processo que tenta abstrair os aspectos particulares dos eventos e detectar

${ }^{5}$ Weinberg, Steven: "Os limites da explicação científica". Folha de São Paulo (Caderno Mais). São Paulo domingo, 24 de junho de 2001, p. 8.

${ }^{6}$ Para essa perspectiva gnoseológica cf. Hartmann, Nicolai: Grundzüge einer Metaphysik der Erkenntnis. Berlin: Walter de Gruyter, 1946, p. 302-306. Adeodato, João Maurício: Filosofia do direito. Uma crítica à verdade na ética e na ciência (através de um exame da ontologia de Nicolai Hartmann). São Paulo: Saraiva, 1996, p. 104. 
neles algo de comum que permita reuni-los em "classes", em "setores" ou coisa que o valha, em suma, classificá-los. Assim é que, mesmo sem ter visto todas as cadeiras que existem na realidade, o ser humano é capaz de, através de operação complexa e ainda não satisfatoriamente explicada, diante de uma cadeira com que nunca teve contato, pensar nela e defini-la como uma cadeira.

Essas idéias, ou como quer que seja denominado o fenômeno, e suas relações com os eventos são por vezes consideradas pelos filósofos ontologicamente, existentes em si mesmas, como no caso das idéias de Platão ${ }^{7}$, ou meras palavras, flatus vocis, como na Escolástica nominalista ${ }^{8}$, ou como resultado de um determinado desenvolvimento cultural que poderia não ter ocorrido, como sugerem Richard Rorty ou Hans Blumenberg, detectando uma atividade seletiva e relativamente arbitrária na escolha dos caracteres principais dos objetos ${ }^{9}$. Tomando a tese de Husserl como exemplo ${ }^{10}$, a redução fenomenológica transcendental consiste em retirar mentalmente do objeto as características acidentais que apresenta para chegar a sua essência enquanto fenômeno colocado diante da consciência cognoscitiva do ser humano. Retirando os aspectos contingentes e individualizadores de todas as cadeiras, acredi-

ta Husserl, chega-se à essência mesma de "cadeira". Todo sujeito procede a operação semelhante quando nomeia e observa os objetos, quaisquer que sejam, ainda que tal atitude não pareça ter o caráter ontológico que Husserl lhe quis imprimir.

Mesmo sendo a idéia geral, ou generalizante, ela ainda é única em relação ao sujeito que a produz, pois cada um seleciona alguns aspectos em detrimento de outros dentre os infinitos atributos que o evento apresenta. Em sua plenitude a idéia é incomunicável, pois o processo de concebê-la e transmiti-la outrem passa por sua vez pela linguagem, a qual já passa a ser um evento da realidade, e submete-a aos critérios relativos do receptor da mensagem, do ambiente e contexto da comunicação, etc.

O termo "conceito" é ambiguamente em pregado, a depender do filósofo, com três sentidos básicos: como o que aqui se denomina "idéia", o que está "por trás" da expressão lingưística, o "primeiro" nível de generalização, se se partir do evento real como referência do ato gnoseológico; ou como essa própria expressão lingüística da idéia, o "segundo" nível de generalização; e ainda observa-se uma sinonímia dominante na linguagem comum, entre "conceito" e "definição", quando, a rigor, definição

7 Platão: Parmenides, in The Dialogues of Plato, translated by Benjamin Jowett, Great Books of the Western World, vol. 6. Chicago: Encyclopaedia Britannica, 1990, p. 486-511. Para Platão os universais existem antes do objetos, diferentemente de Aristóteles, para quem os universais estão nos próprios objetos (teses depois denominadas universalia ante rem e universalia in re, respectivamente).

${ }^{8}$ Russell, Bertrand: History of Western Philosophy - and its Connection with Political and Social Circumstances from the Earliest Times to the Present Day. London: Routledge, 1993, p. 175 s. e 430.

${ }^{9}$ Dentre outros trechos Rorty, Richard: A filosofia e o espelho da natureza, trad. de Antônio Trânsito. Rio de Janeiro: Relume-Dumará, 1994, p. 51 s. Blumenberg, Hans: Die Lesbarkeit der Welt. Frankfurt a. M.: Suhrkamp, 1993 , p. 373 s.

${ }^{10}$ Husserl, Edmund: Ideen zu einer Reiner Phänomenologie und Phänomenologischen Philosophie, Gesammelte Werke, Band III. W. Biemel (Hrsg.). Haag: Martinus Nijhoff, 1956, p. 23-24, e os caps. III (Noesis und Noema) e IV (Zur Problematik der noetisch-noematischen Strukturen), parte III, e § 97, p. 242 s. Também sobre o caráte ôntico da noemática, Husserl, Edmund: Meditaciones Cartesianas, trad. Mario Presas. Madrid: ed. Paulinas, 1979 $\S 43$, p. 152 s. Criticamente Sukale, Michael:Denken, Sprechen und Wissen. Logische Untersuchungen zu Husserl und Quine. Tübingen: J.C.B. Mohr, 1988, p. 272 s.

Revista da Faculdade de Direito da UFRGS, v. 20, Outubro/2001 seria uma tentativa de explicitação analítica dos elementos do conceito a ser definido, lançando mão, por sua vez, de outros conceitos. Aqui vai-se tomar o primeiro sentido, de "idéia", sempre que aparecer o termo "conceito", tentando evitar a imprecisão desse termo. Vai-se também deixar de lado a análise da "filtragem biológica" e da "filtragem ideológica", anteriores a qualquer tratamento linguiístico, as quais parecem ocorrer entre a percepção dos eventos reais e a formação noemática das idéias, tema importante na semiótica contemporânea ${ }^{11}$.

A expressão simbólica comunica a idéia, reintroduzindo-a no mundo real, sempre de maneira incompleta e ainda mais generalizada do que aquela, pois a idéia é ainda individual em relação ao sujeito, enquanto a expressão tem pretensões de comunicabilidade genérica para um determinado universo de receptores dentro de uma linguagem. Não há uma correspondência completa entre a idéia e a realidade, é certo, mas parece haver alguma compatibilidade; um indício neste sentido é que se os cálculos forem assado e não assim, a ponte planejada pelo engenheiro cai. Este um dos grandes problemas que preocupou Kant: como é possível que haja uma correspondência entre fenômenos cerebrais, como cálculos matemáticos, e o mundo rea ${ }^{12}$. A expressão lingüística, por seu turno, parece ser ainda mais distante da realidade individualizada, posto que busca representar e comunicar a idéia, constituindo o segundo nível de generalização mencionado. "Assim, o recurso ao universal não é uma força do pensamento, mas uma enfermidade do discurso. $O$ drama é que o homem fala sempre em geral enquanto as coisas são singulares." ${ }^{\prime 13}$

Ao ser expressada a idéia, ela penetra novamente no mundo sensível e constitui-se por sua vez em evento real, como dito. Então é reiniciado esse processo de conhecimento do mundo. Ciências ideais como as matemáticas puras, por exemplo, têm de se haver apenas com os fatores da idéia e de sua expressão simbólica, posto que não trabalham com eventos reais; já ciências empíricas como a geografia física deparam-se com os três fatores. O direito e outros campos do conhecimento, porém, ainda se deparam com um quarto elemento complicador, trazido pela valoração que os envolve, as perspectivas emocionais diferentes e por vezes antagônicas que as pessoas têm sobre o mundo.

Este outro problema é o abismo axiológico, também decorrente da individualidade humana e de sua criatividade reativa e ativa diante do ambiente, das enormes diferenças entre as pessoas, que são entes reais e cujas atitudes constituem eventos reais. A cultura, em que o direito tem papel fundamental, precisa lidar com essas diferenças e tentar reduzi-las, organizá-las. Um problema gnoseológico apresenta-se, por exemplo, quando se afirma que só a mulher pode ser vítima do crime de estupro, como no atual texto do código penal brasileiro, e é preciso definir se determinada pessoa que sofreu violência sexual no caso concreto é ou não uma mulher, o que pode ser problemático diante dos progressos da medicina. Um problema axiológico surge quando se questiona por que uma pessoa do sexo masculino violentada não deve ser encarada como vítima do crime de estupro, tipificando-se retoricamente o crime como atentado violento ao pudor ou lesão corporal.

${ }^{11}$ Bizzocchi, Aldo: "Cognição - como pensamos o mundo". Ciência Hoje, vol. 30, n 175. Rio de Janeiro: Sociedade Brasileira para o Progresso da Ciência (SBPC), p. 34-40.

${ }^{12}$ Kant, Immanuel: Kritik der Reinen Vernunft,. Werkausgabe - in zwölf Bände, Bd. III, W. Weischedel (Hrsg.) Frankfurt a.M. 1977, S. 76 (A 28, B 44) und 82 (A 35, 36; B 52).

${ }^{13}$ Eco, Umberto: Kant e o ornitorrinco, trad. Ana Thereza Vieira. Rio de Janeiro - São Paulo: Record, 1998, p. 28 
Do ponto de vista do conhecimento, assumido aqui, tentativa de solução é assumir uma perspectiva científica, entendida com um mínimo de partidarismo e a partir de uma atitude na medida do possível neutra e objetiva. Pode-se denominar essa concepção "positivista", excluídas as conotações reducionistas da expressão no campo jurídico.

Nas origens históricas da cultura ocidental, no que concerne ao direito, o abismo axiológico tem sido enfrentado através da no. ção de legitimidade. Da procura, desde a Grécia antiga, por uma instância que separasse o poder efetivo da legitimidade, à distinção romana entre auctoritas e potestas, herdada e transmitida pela grande síntese da Igreja Católica, a cultura ocidental tem sempre procurado uma base que fundamente a legitimidade ${ }^{14}$. Só na modernidade a prática e a teoria do direito passam a reconhecer e afirmar a auto-determinação do direito positivo, evitando como extra-jurídico o problema da legitimidade. A legitimidade não só se confunde com a legalidade enquanto princípio básico mas também com a própria validade das normas jurídicas. $O$ direito passa a ser identificado com aquilo que é produzido de acordo com as regras do sistema, por autoridade declarada competente para tanto e seguindo rito de elaboração específico, estando o sentido das normas inferiores subordinado ao sentido das normas superiores independentemente de seu conteúdo "ideológico", "axiológico", "material". Observe-se o conceito de constitucionalidade material e formal, base de legitimidade, de legalidade, de validade do sistema ${ }^{15}$.

O abismo axiológico reflete-se também na dicotomia entre jusnaturalismo $e$ juspositivismo colocada pela modernidade. $\mathrm{O}$ jovem estudioso espanta-se como podem ser quase todos os pensadores dos últimos duzentos anos positivistas, se todos eram jusnaturalistas nos três mil anos que antecederam esse período. É que o direito mudou muito. Mesmo os mais ferrenhos antipositivistas têm de se haver com o fenômeno da dogmatização do direito e seus corolários. E daí vem a grande questão: se o direito é fruto da vontade do poder empiricamente estabelecido, autodeterminado e autolimitado, ou se há direito acima ou independentemente do poder efetivo. A questão atual da universalidade dos chamados direitos humanos é ilustrativa a respeito ${ }^{16}$.

Pode-se afirmar a existência de direito ou direitos em si mesmos válidos, fora do sistema positivo, direitos que seriam inerentes à própria condição humana; esta ideologia encontra problemas ao se defrontar com a grande diversidade cultural que vem caracterizando as comunidades humanas segundo seu desenvolvimento histórico no tempo e no espaço. Do outro lado, ao afirmar a total subordinação das normas jurídicas às contingências históricas $e$ à luta pelo poder, a ideologia positivista vê-se diante do problema de admitir como jurídico todo e qualquer conteúdo normativo, tal como negar direito à vida a segmentos humanos assemelhados. É o problema do poder constituinte originário incondicionado e da norma fundamental independente de conteúdo axiológico de Kelsen.

${ }^{14}$ Adeodato, João Maurício: O problema da legitimidade - no rastro do pensamento de Hannah Arendt. Rio de Janeiro: Forense-Universitária, 1989, p. 29-52.

${ }^{15}$ Dentre muitos outros v. Silva, José Afonso da: Curso de direito constitucional positivo. São Paulo: Malheiros, 1992, p. 48.

${ }^{16}$ Para uma visão contemporânea da questão, aliada aos direitos naturais, Rabenhorst, Eduardo Ramalho: "Dever e obrigação", in Felipe, Sônia (org.): Justiça como eqüidade - fundamentação e interlocuçôes polêmicas (Kant, Rawls, Habermas). Florianópolis: Insular, 1998, p. 291-300, e Noleto, Mauro de Almeida: Subjetividade jurídica. A titularidade dos direitos em perspectiva emancipatória. Porto Alegre: Fabris, 1998, p. 85-127.

Revista da Faculdade de Direito da UFRGS, v. 20, Outubro/2001
A dogmatização do direito que vem ocorrendo na modernidade parece vir em apoio a esta segunda ideologia. Basta que se observe o conceito de justiça advindo dos tribunais modernos, que são de fato responsáveis pela realização, no sentido literal e filosófico de "torna real", do direito e da norma jurídica. "Justa" é a decisão que toma por base as regras do sistema dogmático positivado pelo poder, seja pelo Talibã, seja pelas cortes de Amsterdã. "Injustiça" permanece, em termos jurídicos, um conceito interno ao próprio direito positivo.

Algumas estratégias podem ajudar a tratar os problemas provocados pelo abismo gnoseológico, as quais serão brevemente sugeridas a seguir.

Uma delas é entender os conceitos descritivos da realidade, claro que incluindo o que é dito aqui, em termos dos Idealtypen de Max Weber. Esses tipos ideais constituem generalizações que, através de abstrações controladas, pretendem reunir unidades reais, em si mesmas incognoscíveis, em conceitos ideais aproximativos. Exatamente porque uma separação precisa não é possível na realidade, os conceitos claros e precisos são mais necessários ainda. Com efeito, o método weberiano imuniza contra a ingenuidade da concepção ontológica, "realista", da língua e ajuda a reduzir pretensões de verdade e a enfrentar com mais segurança o abismo gnoseológico. Só assim a casuística sociológica é possível ${ }^{17}$. É daí que, embora não seja possível encontrar uma sociedade efetivamente legitimada pela via legal-racional weberiana, pode-se dizer que quanto mais institucionalizada a legalidade, mais racional o procedimento legitimador. Da mesma forma,

pode-se enunciar que uma sociedade estará tanto mais em condições de dogmatizar o seu direito quanto mais seus subsistemas estejam reciprocamente imunizados contra as interferências mútuas, mesmo sabendo que, no mundo real, tal imunização jamais ocorre de forma completa.

Em segundo lugar, além de encarar os conceitos como tipos ideais, não se procura aqui definir "o direito" em si, se é que é viável tal tipo de definição, mas simplesmente descrever algumas características de um fenômeno social a que parece se referir esse conceito. Procura-se evitar deste modo a armadilha das definições pretensamente totalizadoras, as quais ou deixam de lado aspectos fundamentais do fenômeno jurídico ou são tão genéricas que, apesar de corretas, em nada auxiliam na compreensão do objeto definido. Definir o direito como "ordenação heterônoma e coercível da conduta humana", "realidade que se refere ao valor do justo", "generalização congruente de expectativas" ou "conjunto de normas coercitivas que possibilita a convivência social", além de atribuir-lhe uma pluralidade de significações definidas, como fazem tradicionalmente os livros de teoria geral do direito ${ }^{18}$, pode até corresponder ao objeto definido, mas pouco ajuda a compreender cientificamente o fenômeno jurídico ou a argumentar dogmaticamente.

Conta-se na Faculdade de Direito do Recife de um exame oral, nos idos da década de vinte, no qual o professor Andrade Bezerra, catedrático de direito civil, teria solicitado de um aluno uma definição do direito. $O$ aluno não teve dúvidas: "é um círculo dentro do qual obramos, mestre". A esta frase teria retorquido o professor: "ora, meu filho, esta é a definição de

${ }^{17}$ Weber, Max: Wirtschaft und Gesellschaft - Grundriss der verstehenden Soziologie. Tübingen: J.C.B. Mohr (Paul Siebeck), 1985, p. 9-10 (I, I, 11).

${ }^{18}$ Reale, Miguel: Lições preliminares de direito. São Paulo: Saraiva, 1994, p. 49; Batalha, Wilson de Souza Campos: Introdução ao estudo do direito. Rio de Janeiro: Forense, 1986, p. 9; Montoro, André Franco: Introdução à ciência do direito, $20^{\mathrm{a}}$ edição refundida com a colaboração de Luiz Antonio Nunes. São Paulo: Introdução à ciéncia do direito, 20 s.
Revista dos Tribunais, $1991, \mathrm{p} .29 \mathrm{~s}$. 
urinol!"'19 . Esta anedota ilustra bem como uma definição omnicompreensiva, ainda que correta, pode induzir em erro e designar idéias inteiramente diferentes. De outro lado, expressões conceituais homônimas podem ser esclarecidos pela definição, a qual as detalha lingüisticamente e permite a diferenciação.

Depois, em terceiro lugar, procura-se privilegiar aqui uma sociologia compreensiva d perspectiva etnometodológica. Etnometodologia entendida como uma perspectiva da sociologia do conhecimento que se interessa pelas obviedades que, por isso mesmo, passam despercebidas, aquelas significações $\mathrm{e}$ pontos de acordo localizados que ficam subentendidos no relacionamento social. O casuísmo da perspectiva etnometodológica procura responder aos novos tempos, nos quais as verdades longa e tradicionalmente aceitas passam a ser questionadas, levando a problemas de "falta de orientação, desorganização e anomia" e tornando fundamental a construção de um novo entendimento sobre temas que pareciam resolvidos, a construção de uma nova realidade e de uma aproximação científica adequada, pois "A confiança naquilo que 'todos sabem' ou 'ninguém faz' começa a desaparecer" 20

Segundo a perspectiva etnometodológica, a realidade deve ser entendida sobretudo como realidade empírica, aquela que se dá no "mundo exterior" e é apreendida pelos órgão dos sentidos e demais portas da percepção. Isto porque os objetos desse mundo exterior, um dos quais é o corpo humano, oferecem resistência e diminuem as possibilidades da livre ação, isso quando não simplesmente as eliminam. A observação de tal realidade não deve se concentrar, de um ponto de vista filosófico, em aspectos materiais da conduta, em conteúdos específicos, pois esses são infinitamente variáveis no tempo e no espaço, necessita procurar abstrair, "idealizar" padrões e expectativas de normalidade e racionalidade. Alguns desses padrões e expectativas parecem, inclusive, ancorados geneticamente em um desenvolvimento das capacidades cognitivas da espécie humana, como, por exemplo, a convicção de que o mundo real independe da opinião pessoal sobre os eventos ocorridos. Outros parecem ter maior interferência do ambiente cultural, por exemplo, a expectativa de que percepções e condutas passadas venham a se repeti em contextos semelhantes ${ }^{21}$. Um estudo mais aprofundado dessa perspectiva ficará para outra oportunidade.

Da outra parte, para tentar tratar dos problemas provocados pelo abismo axiológico mister abstrair de qualquer valoração prévia a questão da modernidade ou da atual pós-modernização globalizada do direito. A modernidade simplesmente trouxe ao direito, fenômeno inerente à sociabilidade humana, como visto, formas próprias de organização. Ser "moderno" não significa ser melhor ou mesmo "mais eficiente" no sentido de efetivamente dirimir conflitos. O direito moderno parece ser o mais eficiente para a sociedade que o produz, apenas isto, esta mesma sociedade que perspectivas jusnaturalistas não conseguem explicar satisfatoriamente. Não se pode dizer que ele torna as pessoas mais ou menos felizes, que ele enseja ou não um desenvolvimento moral ou intelectual mais pleno do ser humano ou da sociedade.
${ }^{19}$ Veiga, Gláucio: História das idéias da Faculdade de Direito do Recife, vol. IX. Recife (no prelo).

${ }^{20}$ Patzelt, Werner: Grundlagen der Ethnomethodologie. Theorie, Empirie und politikwissenschaftlicher Nutzen einer Soziologie des Alltags. München: Wilhelm Fink, 1987, p. 9-14 e 25.

${ }^{21}$ Patzelt, Werner: Grundlagen der Ethnomethodologie. Theorie, Empirie und politikwissenschaftlicher Nutzen einer Soziologie des Alltags. München: Wilhelm Fink, 1987, p. 57.

Revista da Faculdade de Direito da UFRGS, v. 20, Outubro/200
Quando utilizada a expressão "modernidade", então, não há qualquer conotação elogiosa, que a palavra tem adquirido na arrogância da sociedade que se diz moderna, ou pejorativa, como costumam referir os saudosistas de tempos idos.

\section{Pressupostos semânticos paraum conceito instrumental de modernidade}

Relacionando o conceito ao objeto que ele pretende designar, assumem-se aqui dois pontos de partida para tentar definir a modernidade.

Em primeiro lugar, o conceito de modernidade é qualitativo, relativo a um estado inusitado que o direito apresenta enquanto forma de organização social. Em outras palavras, 0 conceito de modernidade não é meramente resultado do fluxo histórico do tempo. Para se "moderna", não é suficiente uma sociedade pertencer aos séculos XIX ou XX, ela precis apresentar certas características específicas em sua estrutura organizacional. Sistemas fundamentalistas contemporâneos, fazendo o direito e a religião inseparáveis, ou Estados embasados em nepotismo e relações de parentesco ou amizade, não são modernos no senti- do aqui empregado, assim como não é pós-moderno isto ou aquilo que acontece na "era da globalização", pois as características da modernidade não dependem de prazos, pontos determinados no tempo. O direito dogmaticamente organizado é o direito moderno por excelência, não por estar onipresente, mas sim pelo seu caráter historicamente inusitado, inexistente na pré-modernidade. $\mathrm{O}$ direito dogmático é moderno mas nem todo direito contemporâneo é dogmático. modernidade não é escatológico. "Escatologia" tem dois sentidos etimologicamente diversos: do grego skór, atós, ou seja, excremento ou caráter relativo a excremento, que obviamente não é o significado aqui; e do grego éscathos, último, isto é, uma "doutrina sobre a consumação do tempo e da história", um "tratado sobre os fins últimos do homem"'22. A atitude de recusar teorias escatológicas parte da compreensão de que a história é imprevisível, nada promete para o futuro, que o futuro enquanto tal não existe, constituindo mero artifício verbal. Não se entende aqui que os parâmetros de organização do direito definidos como modernos constituem um caminho pelo qual evoluirão todos os povos e a sociedade globalizada. Muitos dos sistemas jurídicos alopoiéticos contemporâneos apresentam outras formas também altamente complexas e estáveis, estrategicamente bemsucedidas, de positivação do direito ${ }^{23}$, como
Em segundo lugar, o conceito de

${ }^{22}$ Ferreira Aurélio Buarque de Holanda: Novo Dicionário da Língua Portuguesa. Rio de Janeiro: Nova Fronteira 1986, p. 686, e Meyers Konverstions-Lexicon, fünfter Band. Leipzig/Wien: 1897, p. 996. Para uma ligação do pensamento escatológico ao pensamento teológico, v. Blumenberg, Hans: Die Legitimität der Neuzeit. Frankfurt a. M.: Suhrkamp, 1999, p. 47. Sobre as conexões entre o pensamento metodológico moderno e suas origen teológicas cf. Saldanha, Nelson: Da teologia à metodologia - secularização e crise no pensamento jurídico. Belo Horizonte: Del Rey, 1993, p. 95 s.

${ }^{23}$ Observe-se que o conceito de positivação aqui colocado é mais amplo do que o sentido que lhe parece dar Luhmann, não aparecendo, entre outras diferenças, como corolário do Estado democrático, legitimado procedimentalmente através de constitucionalização, legalização reflexiva do direito ou controle politicamente

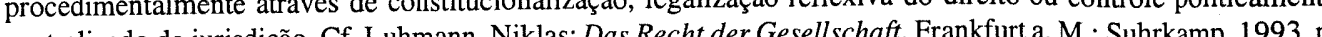
centralizado da jurisdição. Cr. Luhmann, Niklas. Das Rech der Gesellschaf. Frankura. M.: Suhkamp, 1993, p. 38 s., 145-146, 277-278 e 410. Ou anteriormente em Luhmann, Niklas: Legitimation durch Verfahren. Frankfur a. M.: Suhrkamp, 1983 , p. 151 s. 
visto em artigos anteriores ${ }^{24}$.

Além do fato de que não se pode detectar um "caminho histórico" em direção à modernização, poucas formas de organização jurídica existente hoje em dia são modernas no sentido em que o termo é empregado aqui.

Este segundo pressuposto semântico pode ser exemplificado por oposição a concepções holísticas, pretensiosamente dirigidas a explicações não apenas totalizadoras mas ao mesmo tempo previsoras do que está por vir, em uma transposição ingênua e mais do que indevida de categorias (no sentido de "vícios do pensamento") fisio-químico-biológicas a realidades mais complexas e imprevisíveis. São resquícios do intrincado relacionamento entre o pensamento escatológico antigo e os "sucessos" de formas científicas modernas, "dominadoras da natureza", o qual gerou concepções da história tão diferentes entre si como as do cristianismo, com sua concepção de juízo final, justiça aos bons que sofrem nesta vida $e$ aos maus que têm saúde, amigos, poder, aind que a observação empírica não lhes dê respaldo; do liberalismo, com uma escatologia otimista de progresso comandado pelo "mercado", entidade metafísica no mais intrincado sentido do termo, guia da história e da "evolução" da humanidade; do marxismo, prevendo a espiral histórica do feudalismo ao comunismo, passando pelo capitalismo e pelo socialismo; do darwinismo, detectando uma linha evolutiva determinada pela adaptação do ser vivo ao meio ambiente. E ainda outros.
Mais procedente parece conceber a história da humanidade conforme ilustrada pelo mito grego de Sísifo. Este rei de Corinto fo condenado por Zeus a ficar eternamente no Hades, arrastando montanha acima uma rocha que sempre the escapava e rolava montanh abaixo antes de atingir o topo. O motivo do castigo seria ter revelado o rapto de Egina a seu pai, o deus-rio Asopo, sendo Zeus o raptor segundo outros relatos, Sísifo teria enganado e aprisionado Hades, o próprio deus da morte, fazendo com que, durante certo tempo, ninguém morresse ${ }^{25}$. A pedra representa a história, repleta de altos e baixos, avanços e recuos; Sísifo é a humanidade; a montanha é o mundo.

Perguntar-se-á, então, por que estudar a modernidade jurídica, dogmatizada nessas características que serão aqui adiante expostas, se ela existe de fato em apenas alguns países e se nada garante será efetivada nos demais. Dentre outras, cabe ressaltar três motivações principais.

A um, os Estados que dogmatizaram seu direito parecem deter a supremacia militar, ideológica e política do mundo atual. A dogmatização do direito constituiu-se em um instrumento importante para a eficiência do padrão europeu. Parece ser um dos fatores importantes para o domínio relativamente recente da cultura branca européia sobre o mundo, ao lado da resistência a doenças, do desenvolvimento da ciência e dos meios de violência que ela proporcionou, o desenvolvimento da dogmática jurídica. Da mesma forma que se tem notícia de
${ }^{24}$ Adeodato, João Maurício: "Para uma conceituação do direito alternativo". Revista de Direito Alternativo, $\mathrm{n}^{\circ} 1$ São Paulo: Acadêmica, 1992, p. 157-174; "Uma teoria (emancipatória) da legitimação para países subdesenvolvidos". Anuário do Mestrado em Direito, $\mathrm{n}^{\circ}$ 5. Recife: Universitária da UFPE, 1992, p. 207-242; "Unbeständigkeitsstrategien in Rechtssystemen der Peripherie: eine Form alternativen Rechts". Verfassung und Recht in Ubersee, 32. Jahrgang, 3 Quartal 1999. Baden-Baden: Nomos Verlagsgesellschaft, 1999, p. 335-346. ${ }^{25}$ Hamilton, Edith: Mitologia, trad. de Jefferson Camargo. São Paulo: Martins Fontes, 1995, p. 460, e Pinsent, John: Mitos e lendas da Grécia antiga, trad. de Octavio Casado. São Paulo: EDUSP/Melhoramentos, 1978, p. 49 50 .

Revista da Faculdade de Direito da UFRGS, v. 20, Outubro/2001 jovens japoneses, para dar um exemplo, pertencentes a uma cultura milenar e muito mais antiga do que a européia, submetendo-se a operações plásticas para arredondarem os olhos e se parecerem com Elvis Presley, vêm-se sistemas jurídicos asiáticos adotarem o habeas corpus ou as ações de inconstitucionalidade como estratégias importantes.

A dois, um número de Estados muito maior do que aqueles que realmente modernizaram seu direito apresentam-se como se de fato o tivessem dogmatizado. Portanto, a mera aparência de dogmatização e sua adoção enquanto discurso parecem ser funcionais política e juridicamente falando. Se a efetiva dogmatização do direito tem se mostrado um poderoso instrumento estratégico, também é eficiente o șimples apresentar-se dogmático o sistema.

A três, a chamada globalização vem tendo como uma de suas vias a imposição desse padrões de modernização jurídica a todos os Estados participantes, restando a marginalização da comunidade internacional àqueles que não o fizerem. $O$ direito dogmático passa a ser um elemento importante de inclusão/exclusão no mundo globalizado, no padrão de aferição do grau de civilização de uma sociedade, servindo com pré-condição inclusive para o comércio e a atração de investimentos. Aí interrelacionam-se questões econômicas temas éticos como o respeito aos direitos humanos. Compreender esses padrões de pensamento jurídico é útil inclusive para países cujo direito não é dogmático, sejam porque pretendem dogmatizá-lo, como parece ser o caso do Brasil, seja porque pretendem manter-se afastados disto, como parece ser o caso de países fundamentalistas.

${ }^{26}$ Merkel, Adolf Julius: Grundlagen des Rechts, vol. I dos Gesammetten Schriften, (Dorohea Mayer-Maly, Herbert Schambeck e Wolf-Dietrich Grussman - Hrsg.). Berlin: 1993, p. 437 s. ("Prolegomena einer Theorie de rechtlichen Stufenbaues"); Kelsen, Hans: Reine Rechtslehre, 2. Auflage, Wien 2000, p. 228 s. (V, 35, "De (techeral das normas, trad. de José Florentino Duarte. Porto Alegre: Fabris, 1986, p. 323 s. (59, I).
Pode-se supor, por outro lado, que o Estado nacional enfraquece-se contemporaneamente e que a globalização do direito virá a eliminar essas formas de organização social sob as quais vivemos, dentre as quais sobressai-se, conforme visto, a dogmática jurídica. Mas também é possível supor que, ao contrário, a globalização econômica virá a exigir cada vez mais uma globalização jurídica e que esta partirá, certamente, dos padrões da dogmática estabelecida nos países dominantes política e economicamente. Por tudo isso é importante estudar e conhecer a dogmática jurídica.

\section{Pressupostos sociológicos para dogmatização do direito na modernidade}

Procuram-se agora determinar algumas características básicas que uma sociedade precisa apresentar para que possa vir a dogmatizar eu direito. É necessário enfatizar que falar em pressupostos sociológicos não contradiz de modo algum o que foi afirmado acima contra uma concepção escatológica. Não se está aqui a dizer que uma sociedade que apresente tais pressupostos necessariamente modernizará o seu direito mas sim que terá tal possibilidade; $\mathrm{e}$ que sem sua realização prévia, o direito não poderá modernizar-se.

Inicialmente, a organização dogmática do direito pressupõe uma estrutura piramidal, as normas superiores fundamentando as inferiores, na imagem de Adolf Merkel adotada por Kelsen ${ }^{26}$. Para tanto, surge a necessidade de um centro produtor de normas, de um sistema

Revista da Faculdade de Direito da UFRGS, v. 20, Outubro/200 
para trato com certo tipo de relações previamente determinadas, que decida em última instância sobre questões relacionadas com o próprio sistema, monopolizando a definição do direito. Este centro produtor de normas constitui o Estado, o Estado moderno, caso se queira aplicar o conceito de Estado a formas de organização jurídica anteriores à modernidade.

Este fenômeno vem acompanhado de uma filosofia e de uma convicção relativamente generalizada que procuram separar o direito das demais "ordens normativas" enquanto objeto de uma ciência e de um método próprios, assim como de toda uma teoria altamente complexa, a chamada teoria dogmática do direito ou teoria do direito dogmático, que inclui uma hierarquização das fontes do direito, com o privilégio das fontes estatais, a lei e a jurisprudência. A concepção de mundo que subjaz a essas filosofia e teoria geral do direito é o positivismo jurídico estatalista, entendida como aquela perspectiva segundo a qual o único direito existente não é apenas aquele efetivamente empírico, perceptível pelos órgãos dos sentidos, mas sobretudo aquele tutelado pelo Estado.

Ao mesmo tempo em que o Estado responde pelo funcionamento do sistema, é também necessário que seu campo de ação, o direito, esteja relativamente separado, no mundo dos eventos, das demais formas e dicotomias de organização social, ou seja, o segundo pressuposto sociológico para dogmatização é a eman-

cipação, a imunização do direito em relação aos demais agrupamentos de normas.

Daí o segundo pressuposto sociológico importante: uma sociedade só estará potencialmente apta a dogmatizar seu direito se houver uma relativa emancipação do sistema jurídico em relação às demais ordens normativas e aos demais subsistemas sociais, tais como a técnica, a religião, a moral, a etiqueta e os usos sociais, a magia, a posse de bens e riquezas, amizade. Tal faceta de sociedades modernas tem sido descrita como um tipo especial de autonomia do sistema jurídico ou autopoiesis autopoiese ${ }^{27}$. A crer em Luhmann, a inovação do conceito de autopoiese, em relação às teorias anteriores que tomam por base a idéia de auto-organização, é dizer que certos sistemas são capazes não apenas de criar uma ordem autônoma mas também de criar seus próprios elementos.

Não se pretende aqui intervir na discussão sobre se a perspectiva utilizada pela teoria dos sistemas sociais seria ou não fruto de uma adequada transposição de con ceitos biológicos para a teoria do direito ou se essa estratégia das ciências humanas e sociais em geral ajuda ou prejudica sua seriedade e especificidade. Nada obstante, resta evidente que a utilização do conceito de autopoiese aqui indica opção pela aproveitabilidade tanto do conceito específico quanto da estratégia genérica ${ }^{28}$.

${ }^{27}$ Acentuando a distinção entre auto-organização, auto-observação e autopoiese (auto-referência básica), cf. Luhmann, Niklas: Soziale Systeme. Grundriß einer allgemeinen Theorie. Frankfurt a.M.: Suhrkamp, 1984, p. 60 167, 296 e passim. Mais recentemente em sua obra, Luhmann, Niklas: Das Recht der Gesellschaft. Frankfurt M. Suhrkamp, 1995, p 45 s; na p. 62 o autor chama atencão para o sentido confuso da expressão autont M.: Suhrkamp, 1995, p 45 s; Suhrkamp, 1998, p. 810

${ }^{28}$ Sobre o conceito específico de autopoiese, além das referências de Luhmann já feitas, cf. Maturana, Humberto R. e Varela, Francisco J.: Autopoiesis and cognition - The realization of the living. Dordrecht: D. Reidel, 1972, p. $73 \mathrm{~s}$. Sobre a estratégia em geral de aproveitamento de conceitos de um setor do conhecimento por outro cf. criticamente Sokal, Alan \& Bricmont Jean. Imposturas intelectuais - o abuso da ciência pelos filósofos pósmodernos, trad. Max Altman. Rio de Janeiro e São Paulo: Record, 1999, passim, sobretudo o "Prefácio à edição brasileira".

Revista da Faculdade de Direito da UFRGS, v. 20, Outubro/2001
Ainda que toda sociedade possa ser chamada de autopoiética em um primeiro nível, a partir do momento em que a construção do sentido na comunicação vai separando as interações sociais dos indivíduos concretos, refere-se aqui a uma autopoiese de segundo nível, uma "diferenciação funcional". Exemplificando, uma sociedade fundamentalista, por mais indiferenciados que estejam seus subsistemas religioso, moral, jurídico, é autopoiética na medida em que constitui-se a partir da evolução de um sentido consciente para um sentido comunicativo, pois se a consciência é a base da autopoiese dos sistemas psíquicos, a comunicação é a base da autopoiese dos subsistemas sociais. Mas seu direito não o é, por não ser operacionalmente diferenciado de outros códigos comunicativos, como a religião. Uma sociedade como a brasileira, por seu turno, é autopoiética em relação ao ambiente circundante, "natural", mas seu direito também sofre distúrbios alopoiéticos, ou corrupção de códigos quando, por exemplo, subsistema econômico interfere no jurídico, colocando apenas pobres na prisão. Neste sentido, a modernização pode ser compreendida sem prejuízo de outros paradigmas, segundo o modelo da indiferenciação à diferenciação, de uma menor a uma maior complexidade social. Uma sociedade será tanto mais moderna quanto mais diferenciada funcionalmente ${ }^{29}$. Daí, conseqüentemente, mais apta a dogmatizar seu direito.

Não se pense, contudo, que tal fechamento operacional implique um isolamento do direito autopoieticamente organizado em relação aos subsistemas morais ou religiosos ou outros circundantes, mas sim que os critérios para admissão das influências desses outros subsistemas sociais são fixados pelo próprio direito positivo, através de seus procedimentos de modificação e adaptação, tais como novas legislações, jurisdição constitucional e concretizações jurisprudenciais em geral. Quando essa interação acontece sem que haja a corrupção de códigos e a adaptação é funcionalmente bem sucedida, fala-se em acoplamento estrutura ${ }^{30}$. O acoplamento estrutural viabiliza a abertura cognitiva do sistema jurídico, mantendo-o permeável, sensível às influências de novas perspectivas religiosas ou morais, por exemplo, e também influenciando-as, como ocorreu no Brasil em relação à proteção à concubina e aos vínculos homossexuais. Mas essa permeabilidade precisa efetivar-se segundo critérios e procedimentos controlados pelas próprias regras internas do sistema jurídico, tornando necessária uma internalização das novas perspectivas morais, para ficar no exemplo, através de vias dogmáticas como a edição de novas leis ou concretizações jurisprudenciais, configurando o fechamento normativo ${ }^{31}$.

Em outro contexto gnoseológico, podese dizer que "O isolamento de um subsistema (o econômico, o político, o religioso, o jurídico - para somente indicar os principais) é temático. Resulta de uma abstração simplificadora, com fins metodológicos e gnosiológicos." Mas há também “... um automovimento, relativamente independente de agentes externos, como sistema fechado" 32

Este processo de diferenciação, de uma

${ }^{29}$ Luhmann, Niklas e De Giorgi, Raffaele: Teoria della società. Milano: FrancoAngeli, 1995, p. 302 s.

${ }^{30}$ Maturana, Humberto; Magro, Cristina; Graciano, Miriam e Vaz, Nelson (orgs.): A ontologia da realidade. Belo Horizonte: Ed. UFMG, 1997, p. 86-87 (inclui texto com Jorge Mpodozis). Luhmann também utiliza destacadamente o concito: Luhmann, Niklas: Das Recht der Gesellschaft. Frankfurt a. M.: Suhrkamp, 1995, p. 440 s.

${ }^{31}$ Luhmann, Niklas: "The unity of the legal system", in Teubner, Gunther (ed.): Autopoietic law: a new approach to law and society. Berlin / New York: Walter de Gruyter, 1988, p. 12-35.

${ }^{32}$ Vilanova, Lourival: Causalidade e relação no direito. São Paulo: Revista dos Tribunais, 2000, p. 34 e 36.

Revista da Faculdade de Direito da UFRGS, v. 20, Outubro/2001 
perspectiva histórica, pode ser rastreado por diversas vias. Talvez a primeira delas, em termos de nossa cultura ocidental, seja justamente a separação entre técnica e ética. Observe-se que a distinção não é clara para os gregos, ainda que Aristóteles procure estabelecê-la ${ }^{33}$. Para nós, modernos, é clara a diferença entre a maldade (ética) e a incompetência (técnica), o que na teoria geral do direito, reflete na distinção importante entre dolo e culpa, por exemplo. Se a incompetência que causa danos merece se punida, a maldade merece sê-lo com mais rigor Ainda que, mais recentemente, a distinção jurídica tenha sido esmaecida por teorias como do dolo eventual, que aproxima o desvio ético do desvio de competência, ela permanece como um dos postulados do sistema dogmático. Ja em Paulo de Tarso encontra-se nítida a diferença ${ }^{34}$.

Também são os primeiros cristãos os responsáveis pela diferenciação entre religião direito, apontada pelos evangelhos católico através de célebres frases atribuídas a Jesu Cristo, para quem a distinção já parecia pioneiramente clara: "o meu reino não é deste mundo" 35 ou "a César o que é de César, a Deus o que é de Deus" 36 .

Com a expansão do cristianismo, a Igreja assume a guarda da auctoritas, fonte da legitimidade, deixando aos poderes seculares potestas. Etimologicamente, inclusive, não há

distinção entre legalidade e legitimidade, pois legitimus-a-um parece exatamente ter significado "de acordo com a lei" 37 , ainda que só na modernidade isso se explicite com os sistemas dogmáticos, conforme mencionado acima. Os reis bárbaros europeus freqüentemente se viam envolvidos em disputas e guerras dinásticas, fazendo importantes as regras e a intervenção da Igreja. O poder temporal da Igreja Católica, contudo, internacional e coercitivo nos tribunais do Santo Ofício, retarda de alguma maneira a diferenciação entre religião e direito.

É justamente esta posição acima do poder efetivo que se constitui em um entrave à ascensão do Estado moderno, quando tornase mais aguda a necessidade de separação e os primeiros juristas da modernidade esforçam-se por distinguir com nitidez a fronteira entre a esfera de ação da Igreja e a esfera de ação do Estado emergente, soberano e leigo. O protestantismo já surge dividido em termos nacionais e sua convivência com os Estados soberanos, para não dizer subordinação, jáémais pacífica. Mesmo assim, na França católica, observe-se que é de Napoleão I, em tempo relativamente recente e já na era moderna, 2 de dezembro de 1804 , o gesto emblemático de demonstrar publicamente que dispensava a auctoritas e a legitimação da Igreja, ao retirar no último instante a coroa de imperador das mãos do papa Pio VII e coroar-se a si próprio na catedral de Notre Dame ${ }^{38}$.

${ }^{33}$ Entre outros trechos, Aristóteles: Nicomachean ethics, VI, 4, 1140a, trad. de W. D. Ross, in The Works of Aristotle, coleção Great Books of the Western World, vol. 8. Chicago: Encyclopaedia Britannica, 1990, p. 333-436, Aristotle, coleç

${ }^{34}$ Adeodato, João Maurício: "Ética, jusnaturalismo e positivismo no direito". Anuário dos Cursos de PósGraduação em Direito, $\mathrm{n}^{\circ}$ 7. Recife: Universitária da UFPE, 1995, p. 119-216.

${ }^{35}$ Evangelho de João 18 (36-37) e 19 (11). A edição consultada é a Bíblia Sagrada, trad. Pe. Antonio Pereira de Figueiredo. Rio de Janeiro: Encyclopaedia Britannica, 1987.

${ }^{36}$ Evangelhos de Marcos 12 (17) e Lucas 20 (25).

${ }^{37}$ Ritter, Joachim e Gründer, Karlfried (Hrsg.): Historisches Wörterbuch der Philosophie, Band V. Basel / Stuttgart: Schwabe \& Co. AG, 1980, p. 160-166 (verbete: Legalität, Legitimität). E Lafer, Celso: "Prefácio" a Faria, José Eduardo: Poder e legitimidade - Uma introdução à politica do direito. São Paulo: Perspectiva, 1978, 9-13, p. 9. ${ }^{38}$ Săo muitas as obras históricas que podem ser consultadas. Sugere-se a The New Encyclopaedia Britannica, Macropaedia, vol. 24, Chicago: The University of Chicago, 1989, p. 745.

Revista da Faculdade de Direito da UFRGS, v. 20, Outubro/2001
As próximas distinções, no que concerne às ordens normativas, dão-se entre religião e moral, de um lado, e direito e etiqueta, de outro. $\mathrm{O}$ ateísmo ou a pertinência a outras religiões vai deixando de constituir uma imoralidade, aparecendo pessoas que defendem coerência e rigidez morais sem apelo a qualquer divindade. O ateu deixa de ser necessariamente antiético uma moral laicizada vai se tornando possível.

Da mesma forma, depois de uma preoobjetivando-as em compilações e buscando divulgá-las ${ }^{39}$, aparecem tentativas de estudálas cientificamente e, o que mais aqui interess ressaltar aqui, de separá-las das normas de direito. Isso se torna mais necessário, também, devido às tentativas modernas de emancipar cientificamente o direito, identificando seu objeto específico, posto que os critérios tradicionalmente utilizados diante da religião e da moral (exterioridade, heteronomia, alteridade) não funcionavam diante das normas de uso social, de etiqueta, de bom-tom, exigindo conceitos mais sofisticados como os de coercitividade e bilateralidade para separá-las das normas jurídicas. Assim, no início do século XX já estão mais claras as diferenças entre uso, costume, convenção, direito, dentro do conceito mais amplo de ação social ${ }^{40}$. cupação crescente com as normas de etiqueta,

\section{Diferenças de um direito dogmaticamente organizado}

O direito dogmaticamente organizado apresenta as mais diversas facetas e seu alto grau de diversidade não permite falar de uma evolução homogênea em qualquer direção. Inobstante, dentre suas inúmeras características, cujo grau de importância também varia, cinco serão agora destacadas, apenas de um ponto de vista da retórica analítica e visando sobretudo efeitos didáticos ${ }^{41}$, pois essas condições ou constrangimentos aparecem indissociadamente na realidade jurídica. Eles constituem a visão interna do sistema dogmático ${ }^{42}$.

São eles: em primeiro lugar, fixar textos normativos; em segundo, dizer o que significam os termos que os compõem; em terceiro, argumentar com referência a eles; em quarto, decidir com base neles; em quinto, fundamentá-los, justificando as decisões concretas.

Pode-se, como outros autores, utilizar a expressão direito positivo para designar essa forma estatal moderna de organi-

${ }^{39}$ Roquette, José Inácio: Código do bom-tom ou Regras da civilidade e de bem viver no século XIX (org. Lilia Schwarcz). São Paulo: Companhia das Letras, 1997.

${ }^{40}$ Max Weber: Wirtschaft und Gesellschaft -Grundriss der verstehenden Soziologie. Tübingen: J.C.B. Mohr (Paul Siebeck), 1985, p. 11-15 (I, II, \& $1^{\circ}-4^{\circ}$ ).

${ }^{41}$ Tomam-se por base Ballweg, Ottmar: "Analytische Rhetorik als juristische Grundlagenforschung", in Robert Alexy, Ralf Dreier, Ulfrid Neumann (Hrsg.): Archiv für Rechts- und Sozialphilosophie, Beiheft 44. Sttutgart: Steiner, 1991, p. 45-54, dentre outros trabalhos, o qual ressalta quatro constrangimentos ou Zwänge (Entscheidungszwang, Bregründungszwang, Deutungszwang e Normsetzungszwang); Ferraz Junior, Tercio: Função Social da Dogmática Jurídica São Paulo: Revista dos Tribunais, 1980; e sobretudo a obra de Viehweg, Theodor muito embora esses autores não sejam sequer co-responsáveis pelas presentes colocações.

${ }^{42}$ Repita-se que esses constrangimentos não são suficientes para definição de um estado democrático de direito, cujos elementos (constitutivos, nomocráticos, relacionais) exigem condições mais complexas e específicas, formando uma estrutura organizacional que, se pressupõe a dogmatização, vai muito além dela. Cf. Sobota, Katharina: Das Prinzip Rechtstaat. Verfassungs- und verwaltungsrechtliche Aspekte. Tübingen: Mohr Siebeck, 1997, p. 518.

Revista da Faculdade de Direito da UFRGS, v. 20, Outubro/2001 
zação jurídica ${ }^{43}$ ou, como escolhido aqui, direito dogmático. Isto porque a expressão positividade e seus derivados têm levado a equívocos na literatura jurídica, sendo empregada em sentidos diversos, tais como os de validade, vigência, eficácia, efetividade ${ }^{44}$. Entendese aqui o direito dogmático como uma das formas que pode assumir o direito positivo; direito dogmático é o direito posto pelo Estado moderno segundo tais e tais características, mas o direito pode ser posto por outras instâncias nãoestatais, pode ser atual ou histórico, em suma, exibir múltiplas e diferentes características.

Assim, como primeiro constrangimento, coloca-se a obrigatoriedade de estabelecer textos normativos, fixar previamente os pontos de partida para as regras do jogo. Daí a expressão dogmática jurídica, pois são precisamente esses textos os dogmas que procuram fixar os limites que, apesar de elásticos, não devem ser explicitamente negados. Nos sistemas jurídicos democráticos, informados pela separação dos poderes, tal função fica mais a cargo do poder legislativo e, cada vez mais no mundo moderno, mais ainda nos países subdesenvolvidos, a cargo do poder executivo. Isto porque o poder executivo, além de estabelecer textos genéricos tal e qual o legislativo, como nas medidas provisórias no Brasil, ainda cuida de reduzir o grau de generalidade, no caminho da concretização, da especificação realizadora da norma, através de decretos regulamentadores que, em certas áreas, também são de sua competência constitucional. Isto sem contar quando decide mes- mo, especificando o texto, criando a norma em sua concretude, aí já no constrangimento a decidir. Este primeiro constrangimento, assim, não consiste exatamente em fixar as normas e sim apenas seu texto, seus pontos de partida lingüísticos.

Em segundo lugar, a obrigatoriedade de dizer o que o texto da norma significa efetivamente, pois ele não é "portador" da norma mas sim um meio para interpretações diversas e concorrentes entre $\mathrm{si}^{45}$. O sistema jurídico precisa determinar o sentido real do texto normativo previamente fixado e agora alegado diante do caso concreto, colocando em que medida concreta ele deverá pautar as condutas e os conflitos a respeito dos quais os textos são mencionados. É a obrigatoriedade de interpretar os textos normativos. Esses textos apresentam-se com diferentes graus de generalidade e é difícil dizer exatamente quando se concretizam, o que não invalida o constrangimento dogmático. A disparidade entre as interpretações possíveis leva muitas vezes o ambiente social a uma perplexidade que pode até prejudicar a necessidade de fundamentação, a legitimação da decisão. Mas, de qualquer modo, toda decisão diante do caso concreto provém de determinada interpretação.

Note-se, sobretudo mas não unicamente nos países periféricos, que muitas vezes os próprios juízes e demais agentes jurídicodogmáticos são limitados intelectualmente para esta difícil tarefa concretizadora e prendem-se a

${ }^{43}$ Luhmann, Niklas: "Positivität des Rechts als Voraussetzung einer modernen Gesellschaft", in Luhmann, Niklas: Ausdifferenzierung des Rechts - Beiträge zur Rechtssoziologie und Rechtstheorie. Frankfurt a.M.: Suhrkamp, 1981, pp. 113-154; mais recentemente, já com o conceito autopoiético de "fechamento operativo do sistema jurídico", Luhmann, Niklas: Das Recht der Gesellschaft. Frankfurt a. M.: Suhrkamp, 1995, p. 38 s.

${ }^{44}$ Alexy, Robert: Begriff und Geltung des Rechts. Freiburg / München: Alber, 1992, p. 31 s. divide os positivistas em duas grandes vertentes: aquela primariamente orientada para a efetividade (Wirksamkeit) e a primariamente orientada para o estabelecimento (Setzung), a validade da norma. Sobre a ambigüidade do conceito de positividade, cf. Silva, José Afonso da: Aplicabilidade das normas constitucionais. São Paulo: Malheiros, $3^{\mathrm{a}}$ ed., s/d, p. 63-66. ${ }^{45}$ Müller, Friedrich, Christensen, Ralph e Sokolowski, Michael: Rechtstext und Textarbeit. Berlin: Duncker \& Humblot, 1997, p. 19 s.

Revista da Faculdade de Direito da UFRGS, v. 20, Outubro/2001

um formalismo silogístico que, já inadaptado a um regime ditatorial subdesenvolvido como aqueles que aqui e ali têm pontificado na América Latina, mostra-se inteiramente incapaz de responder às demandas sociais do direito dogmático que caracteriza as democracias modernas ${ }^{46}$.

Em terceiro lugar, a obrigatoriedade de só argumentar tomando por base ealegando expressamente esses textos normativos pré-fixados. A validade dogmática de um argumento não está previamente condicionada a critérios externos como justiça, verdade científica, racionalidade ou mesmo a fatos concretos, daí a independência da "verdade" jurídica em relação à "realidade", exemplificada pelo brocardo "o que não está nos autos não está no mundo". Essa autonomia ou fechamento do sistema dogmático leva a procedimentos absurdamente formalistas aos olhos do leigo, que não aceita a idéia de seu direito ser negado por perda de prazo, incompetência ou outros defeitos no processo.

Em quarto lugar, o constrangimento a decidir todo e qualquer conflito considerado juridicamente relevante pelo sistema, a também chamada proibição do non liquet $t^{47}$. A atitude de Pilatos, lavando as mãos ${ }^{48}$, não é opção admissível para um juiz dogmático, dentro de sua esfera de competência. O juiz moderno não deve poder dizer jus non liquet ("o direito não está claro"), não está entre suas possibilidade dizer "não sei." Uma das diferenças básicas entre os textos dogmáticos e os demais é precisamente essa necessidade de decidir todo qualquer problema juridicamente relevante. Não se devem confundir textos jurídicos dogmáticos, que precisam responder (dokein) decisivamente a pro-

${ }^{46}$ Krell, Andreas: "10 Jahre brasilianische Bundesverfassung: Rechtdogmatische und rechtssoziologische Aspekte der Entwicklung des Grundrechtsschutzes". Verfassung und Recht in Übersee, 32. Jahrgang, 1. Quartal. BadenBaden: Nomos, 1999, p. 7-30, p. 15

${ }^{47}$ No direito positivo brasileiro, cf. Lei ${ }^{\circ} 5.869$, de 11 de janeiro de 1973 (Código de Processo Civil), art. 126. São Paulo: Saraiva, 1997, e o art. $5^{\circ}, \mathrm{XXXV}$, da Constituição Federal de 1988 (atualizada até a Emenda Constitucional 30/2001). São Paulo: Juarez de Oliveira, 2001.

${ }^{48}$ Evangelho de Mateus 27 (24). Mateus é o único dos evangelistas que se refere à ablução quando Jesus 6 levado a Pilatos. Observem-se os Evangelhos de João 19 (1-16), Lucas 23 (1-25) e Marcos 15 (1-15).

${ }^{49}$ Ballweg, Ottmar: "Analytische Rhetorik als juristische Grundlagenforschung", in Alexy, Robert, Dreier, Ralf e Neumann, Ulfrid (Hrsg.): Archiv für Rechts- und Sozialphilosophie, Beiheft 44. Sttutgart: Steiner, 1991, p. 50. Revista da Faculdade de Direito da UFRGS, v. 20, Outubro/2001 

constitucionais $^{50}$. Esses textos apenas sugerem sigquestão. O sistema jurídico-dogmático da mentação mais ou menos definidas, comoquer Alexy, ou se se trata de uma neutralização que institucionaliza o dissenso por meio de um procedimento autopoieticamente organizado, como quer Luhmann, essa é uma discussão que não cabe travar aqui. Isso sem contar as análises combinatórias conceituais levadas a efeito por autores menores. Agora basta fixar que o plexo normativo dogmático leva esta fundamentação a efeito ampliando cada vez mais a vagueza e a ambigüidade dos textos fundantes, culminando nas referências aos princípios expressos nos textos nificados, a partir de estruturas lingüísticas entimemáticas, as quais vêm a ser concretamente preenchidas segundo as peculiaridades do caso em modernidade é constrangido a isso justamente em função de sua relativa emancipação dos demais subsistemas normativos sociais, afastando o problema dos conteúdos éticos específicos. Ao perder suas bases éticas comuns em uma ambiente socia grandemente diferenciado, no qual as pessoas e os grupos humanos não concordam sobre questões vitais para a vida em comum, as normas jurídicas precisam de um alto grau de maleabilidade interpretativa.

O problema da fundamentação está relacionado com o abismo axiológico de que foi falado acima, constituindo-se no mais hetero-referente do constrangimentos dogmáticos, a ponto de positivistas considerarem a questão da fundamentação uma questão extra-dogmática. Mas esta é uma simplificação indevida, ainda que a questão da legitimidade constitua-se em um dos pontos cruciais de abertura e comunicação entre o sistema dogmáticoe o sistema político, dentre outros. De toda forma, a dogmática, como procedimento jurídico de solução de conflitos, o positivismo, enquanto perspectiva teórica e filosófica, e ademocracia, comoregime po-

lítico, parecem estar umbilicalmente ligados na organização e compreensão do direito na modernidade, sem esquecer as formas pré-modernas existentes hoje. Mas o problema da legitimidade, escamoteado e descartado pelo positivismo ortodoxo, na medida em que é equacionado em termos de legalidade e mera validade intra-sistêmica, vem se constituindo em problema crucial para o direito da pósmodernidade, cada vez mais complexo. Isso não deve aqui significar uma visão negativa e desiludida dos tempos futuros, nem a uma visão otimista iluminada ${ }^{51}$.

Ainda assimnote-se que, mesmo nos Estados democráticos do centro desenvolvido, a dogmatização do direito constitui um tipo ideal, uma ficção, uma estratégia retórica de controle social que se tem mostrado funcional $e$ eficiente nos mais diversos contextos. Mas daí a crer que é real e verdadeira, construindo uma teoria social ou jurídica omnicompreensiva a partir dela, vai uma grande distância. O mesmo vale para os demais tipos ideais discutidos aqui, incluindo o Estado democrático de direito.

Mais ainda, se a dogmática jurídica e o Estado moderno têm seus dias contados na pós-modernidade ou se haverá uma adaptação crescente aos novos desafios, com uma maior abertura do direito em função de um acoplamento estrutural mais abrangente, por exemplo, através de uma jurisdição constitucional cada vez mais embasada em princípios ou de procedimentos alternativos de solução de conflitos, só o futuro dirá. Mesmo deixando de lado as escatologias, pode-se dizer que a organização dogmática do direito incorporase definitivamente ao patrimônio cultural desses tempos modernos.

${ }^{50}$ Para uma posição mais confiante na "força normativa" dos princípios, Streck, Lenio Luiz: Hermenêutica jurídica e $(m)$ crise. Uma exploração hermenêutica da construção do direito. Porto Alegre: Livraria do Advogado, 2000, p. 224-239.

${ }^{51}$ Para referências no sentido de uma conceituação da "pós-modernidade", cf. Apostolova, Bistra Stepanova: Poder judiciário: do moderno ao contemporâneo. Porto Alegre: Fabris, 1998, p. 25-37.

Revista da Faculdade de Direito da UFRGS, v. 20, Outubro/2001

\section{O Novo Código Civil Brasileiro: em busca da "Ética da Situação"}

\author{
Gudith Martins-Costa
}

"A 'ética da situação' inspira e governa a estrutura do Projeto, obedecendo à exigência atual do 'Direito como concreção', ou, como prefiro dizer, do 'Direito como experiência', inexistencial". (Miguel Reale)

\section{Introdução}

O velho "Código de Beviláqua", o ainda vigente Civil Brasileiro ${ }^{2}$, tido por Pontes de Miranda ${ }^{3}$ como "o antepenúltimo código oitocentista" - muito embora tendo entrado em vigor em 1916 - por seu espírito individualista, liberal em matéria econômica, conservador ao extremo nas relações familiares, está prestes a se transformar numa referência histórica. Acaba de ser finalmente votado pelo Congres-

so Nacional o Projeto de Lei $\mathrm{n}^{\circ}$ 635-/75, que institui o novo Código Civil Brasileiro.

O novo Código, contendo 2.046 artigos, resulta de Anteprojeto elaborado por Comissão de Juristas presidida por Miguel Reale. Para compreendê-lo, mister um olhar sobre as suas origens, que recuam, no tempo, à década de 60 , quando se fez mais forte a compreensão da necompativel com disposições que levam em conta relações formais, com olvido de seu conteúdo

${ }^{1} O$ presente estudo foi originalmente elaborado para integrar volume acerca da codificação nas Américas, a ser publicado na Revista Jurídica de la Universidad Interamericana de Puerto Rico, tendo sido também publicado na Revista Jurídica vol. 282, Porto Alegre, 2001. Em razão da recente aprovação do texto proposto e consolidado pelo Relator Geral, Deputado Ricardo Fiúza, pela Câmara dos Deputados em 15 de agosto de 2001, foram agora atualizados o título e as referências já ao "novo Código", remodelada, em parte, a estrutura do trabalho e acrescidas considerações. Agradeço o auxílio de Laura Beck Varela na revisão das notas.

2 O vigente Código Civil resultou do trabalho de Clóvis BEVILÁQUA. Convidado em 1899 pelo Governo Brasileiro para a sua elaboração, deveria aproveitar o quanto possível dos Projetos anteriores, desde a ConsoBrasileiro para de NABUCO DE ARAÚJO (1872), FelKCOO dOS SANTOS (1881) C COELO elaborou a sua obra em poucos meses. Submetido a duas revisôes, o Projeto fol enviado em 1900 ao Congresso Nacional, lá tramitando por 15 anos, até que em 26 de dezembro de 1915 foi aprovado, sendo sancionado em $1^{\circ}$ de janeiro de 1916 e entrando em vigor um ano após.

${ }^{3}$ PONTES DE MIRANDA, F.C, Fontes e Evolução do Direito Civil Brasileiro, Rio de Janeiro, Forense, 1981 , p. 85 . 